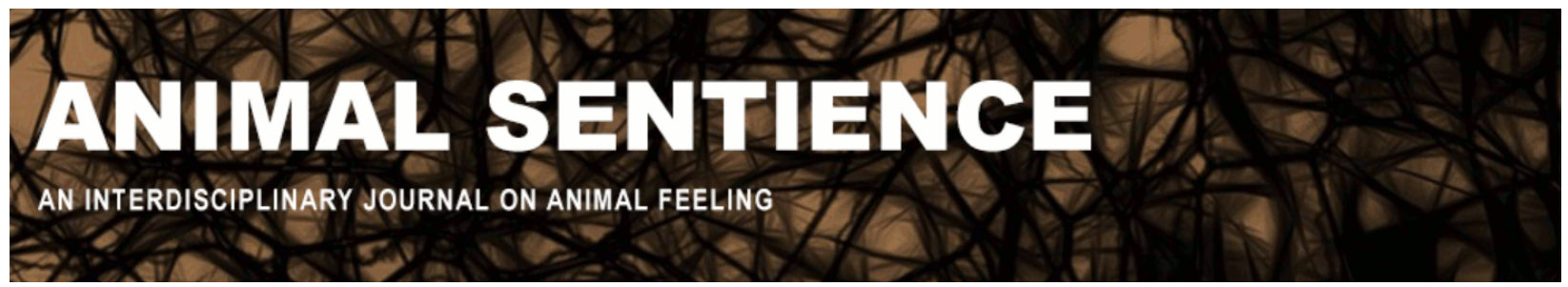

Faria, Catia (2016) Why we should not postpone awareness of wild animal suffering. Animal Sentience 7(14)

DOI: 10.51291/2377-7478.1099

Date of submission: 2016-03-07

Date of acceptance: 2016-06-30

(c) (†)

This article has appeared in the journal Animal

Sentience, a peer-reviewed journal on animal

cognition and feeling. It has been made open access,

free for all, by WellBeing International and deposited

in the WBI Studies Repository. For more information,

please contact

wbisr-info@wellbeingintl.org.

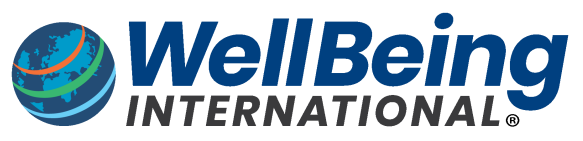

SOLUTIONS FOR PEOPLE, ANIMALS AND ENVIRONMENT 


\title{
Why we should not postpone awareness of wild animal suffering
}

Commentary on $\mathrm{Ng}$ on Animal Suffering

\author{
Catia Faria \\ Department of Law \\ Pompeu Fabra University, Spain
}

\begin{abstract}
Ng (2016) restates his case for the importance of wild animal suffering (1995). Nevertheless, he suggests that the most effective way to reduce nonhuman suffering overall is to give short-term priority to the suffering of farmed animals. It is not clear that Ng puts forward a successful case. Our current efforts to prevent animal suffering overall should also include raising awareness of wild animal suffering now as well as promoting research on safe and feasible ways to prevent wild animal suffering in the future.
\end{abstract}

Catia Faria is a researcher in animal ethics at the Law Department of Pompeu Fabra University (Spain). She is also an associate researcher of the Political Theory Group at the University of Minho (Portugal). http://upf.academia.edu/catiafaria

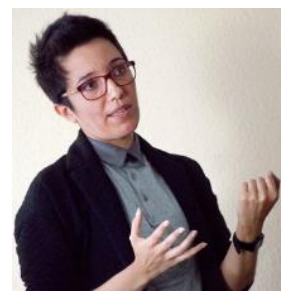

Until very recently, animal suffering and death in the wild have not been seen as morally problematic. It was Yew Kwang Ng's seminal article in 1995 that triggered awareness about wild animal suffering, in particular, how it is determined by population ecology. Ng argued that the dynamics of animal populations are the most important cause of suffering and early death in the wild. Population dynamics may be optimal for the sake of natural processes, yet they make animal suffering rather than well-being largely prevail in nature.

In his ASent target article, Ng (2016) revises the implications of accepting this claim. He suggests that even though wild animal suffering is a moral priority, it is more effective to focus our concern on the suffering of farmed animals instead:

"Being much more numerous, wild animals are much more important in general and in the long term. However, as a near-term strategy, I suggest that, without ignoring wild animals altogether, our initial emphasis should be more on farmed animals, for a number of reasons" (Ng 2016: 7).

The first reason $\mathrm{Ng}$ advances in support of this view is that we are in closer contact with farmed animals and directly responsible for their suffering and deaths. Thus, Ng concludes, we are likelier to "gain converts more easily on this front." It is true that we are directly responsible for the suffering inflicted on animals under human control, whereas we are not causally linked in the same way to the natural harms wild animals suffer. According to some views, this would give us a stronger moral reason to prevent or alleviate the suffering of farmed animals. However, this is not the kind of consideration $\mathrm{Ng}$ has in mind. Rather, his 
argument is based on the effectiveness of strategies for spreading concern about nonhuman animals.

With that in mind, it is not clear that causal responsibility for harm makes someone more likely to be persuaded to minimize it, or to stop it altogether, as Ng suggests. In the case of harms caused by humans to other animals, people may be less willing to undertake big changes in their daily habits, such as the food they eat. On the other hand, concern for wild animals does not have such a salient impact on our daily practices. Hence people might be more inclined to act on it. Surely we lack accurate data to back up either of these predictions. Until we do, however, it is unclear whether it is strategically preferable to follow one path (focusing on farmed animals) over another (advocating for animals in the wild as well).

$\mathrm{Ng}$ 's second rationale for emphasizing farmed over wild animal suffering is our limited knowledge on how to help wild animals today. This is partly true. We currently "have less knowledge of wild animals and less influence over them" (Ng 2016: 7). Nevertheless, there are ways of helping wild animals already available to us on a micro or medium scale, such as rescues, medical intervention to help the injured, vaccination programs, and supplementary feeding of animals suffering from extreme weather conditions. Moreover, ignorance regarding large-scale interventions to alleviate wild animal suffering is not a rationale for emphasizing the suffering of farmed animals over the suffering of those living in the wild. If it is true, as $\mathrm{Ng}$ claims, that due to their high numbers wild animals are much more important in the long term, Ng provides us with very strong reasons to promote the requisite research for potential future evidence-based interventions to help them.

Finally, Ng mentions the potential risk of currently focusing on wild animal suffering. Since interventions to help wild animals could have long-term ecological repercussions, we should defer measures to help them until a better informed future, according to Ng (2016), "after much greater concern for farmed animals has become the norm, legally and culturally" (7).

There are several issues at stake here. First, since our concern is with preventing or reducing animal suffering, the mere fact that a certain intervention in nature may have long-term ecological repercussions is, in itself, neither positive nor negative. That would depend on whether its effects on wild animals are, overall, beneficial or detrimental to their well-being. At any rate, even if one conceded that intervening now would, on many occasions, harm wild animals more than it would help them, it would still not follow that our focus should be predominantly on farmed animals. Again, given the long-term importance of wild animal suffering, that would give us very strong reasons to do research on how to make it more feasible to carry out future long-term sustained interventions to benefit wild animals.

Second, Ng believes that we can spread concern for wild animals more effectively after more concern for farmed animals becomes the legal and cultural norm. Yet if it were true that concern for farmed animals automatically led to concern for wild animal suffering, one might confidently expect to find great concern for wild animal suffering among, for instance, animal ethicists. Nevertheless, with some exceptions (e.g., Cowen 2003, Nussbaum 2006, Horta 2010), animal ethicists usually fail to see that wild animals are in need. Prominent examples include Regan (2004 [1983]), Clark (1977), Adams and Donovan (2007), Francione 
(2000), and Dunayer (2004). Donaldson and Kymlicka (2011) are only partially aware of the problem. The underlying belief that seems to be shared by these theorists - often referred to in the literature as "the idyllic view of nature" - is precisely the one that $\mathrm{Ng}^{\prime}$ 's seminal work aimed at debunking, by showing that the aggregate value of wild animal well-being is net negative.

Thus, even if $\mathrm{Ng}$ is right that raising awareness of farmed animal suffering will increase longterm concern for wild animal suffering, it does not follow that people will recognise that there is also reason to intervene in nature to help. Awareness also needs to be raised about how animals fare in the wild, by showing the evidence that counters the idyllic view of nature. People will care about wild animals only to the extent that they know the truth about their suffering.

\section{References}

Adams, C. J. \& Donovan, J. (Eds.). (2007). The feminist care tradition in animal ethics: $A$ reader. New York: Columbia University Press.

Clark, S. R. L. (1977). The moral status of animals. Oxford: Oxford University Press.

Cowen, T. (2003). Policing nature. Environmental Ethics, 25, 169-182. doi: 10.5840/enviroethics200325231

Donaldson, S. \& Kymlicka, W. (2011). Zoopolis: A political theory of animal rights. Oxford: Oxford University Press.

Dunayer, J. (2004). Speciesism. Derwood: Ryce.

Francione, G. L. (2000). Introduction to animal rights: Your child or the dog? Philadelphia: Temple University Press.

Horta, O. (2010). Debunking the idyllic view of natural processes: Population dynamics and suffering in the wild. Telos, 17(1), 73-90. http://dx.doi.org/10.15304/t.17.1.284

Ng, Y.-K. (1995). Towards welfare biology: Evolutionary economics of animal consciousness and suffering. Biology and Philosophy, 10, 255-285. http://dx.doi.org/10.1007/bf00852469

$\mathrm{Ng}$, Y.-K. (2016). How welfare biology and commonsense may help to reduce animal suffering. Animal Sentience 2016.007.

Nussbaum, M. C. (2006). Frontiers of justice: Disability, nationality, species membership. Cambridge: Harvard University Press.

Regan, T. (2004 [1983]). The case for animal rights. Berkeley: University of California Press. 